\title{
A family study of Paget's disease of bone
}

\author{
J A SOFAER, ${ }^{12}$ S M HOLLOWAY, ${ }^{2}$ AND A E H EMERY ${ }^{2}$ \\ From the Department of Oral Medicine and Oral Pathology, ${ }^{1}$ University of Edinburgh, Edinburgh EH1 1 NR \\ and the University Department of Human Genetics, ${ }^{2}$ Western General Hospital, Edinburgh EH4 $2 X U$
}

SUMmaRY Familial aggregation of Paget's disease of bone occurs occasionally and an exclusively genetic aetiology has been proposed in the past. On the other hand, epidemiological surveys point to an important environmental contribution, and evidence is accumulating to suggest that the disease may be caused by a slow virus infection. Analysis of 407 family history questionnaires completed by patients with Paget's disease confirmed the familial nature of the disease. Overall, the findings were consistent with the hypothesis that Paget's disease is caused by infection with a common and widespread virus superimposed on genetic variation for susceptibility and perhaps severity of the disease.

Paget's disease of bone is a remarkably common condition in later life, radiological surveys having detected characteristic bony changes in $2 \cdot 3-8 \cdot 3 \%$ of the British population at age 55 and above, with a moderate male predominance $\left(\sigma^{\prime} / \rho=1 \cdot 59\right) .{ }^{1}$ The disease involves rapid remodelling and the development of structurally abnormal bone, and can be the cause of pain, fracture deformity, and, rarely, malignancy. Many affected individuals are asymptomatic, but because of its high prevalence the disease still makes a considerable contribution to morbidity among the elderly. ${ }^{2}$

Paget's disease shows a degree of familial aggregation, including occurrence in successive generations, and has consequently been listed as a possible autosomal dominant disorder. ${ }^{3}$ Genetic linkage has also been suggested between a presumed Paget's disease locus and the HLA complex on chromosome $6 .^{4}$ On the other hand, there is increasing evidence of an important environmental contribution. For example, prevalence among migrants from the United Kingdom to Australia, although higher than for native Australians, is lower than for British residents ${ }^{5}$; and within Britain there is a remarkably localised area of particularly high prevalence in Lancashire. ${ }^{1}$ In the United States blacks and whites show similar prevalences that vary from one part of the country to another, even though the disease is rare among African blacks. ${ }^{6}$

The most exciting recent finding is ultrastructural and immunohistological evidence of viruses within the osteoclasts of affected bone, suggesting that Paget's disease may be caused by a slow virus infection. ${ }^{7}$ Two different viruses have been implicated, measles virus ${ }^{8}$ and respiratory syncytial virus. ${ }^{9}$ This apparent inconsistency is a little puzzling, although very recent work suggests that the two viruses may have an antigen in common. ${ }^{10}$ Attempts to show raised viral antibody titres in the serum of patients with Paget's disease have been unsuccessful for measles, ${ }^{11} 12$ whereas for respiratory syncytial virus there have been conflicting results. ${ }^{12} 13$

The present study was undertaken in the hope of gaining further information on the aetiology of Paget's disease. It differs from previous work in that an attempt has been made to analyse both genetic and environmental influences on the disease within the same sample.

\section{Subjects and methods}

During 1980 and 1981,595 family history questionnaries were distributed to known sufferers of Paget's disease, almost all of whom were ascertained through the British National Association for the Relief of Paget's Disease. Questions were asked about the index cases, their first degree relatives, their spouses, and their spouses' first degree relatives. For each index case or relative the information requested included: year of birth, sex, place of birth, main place of residence in each of three different age ranges, occupation, any chronic illness other than Paget's disease, and, if affected by Paget's disease the age of onset and any illness or unusual circumstances that occurred within the year before onset of Paget's disease. Respondents were not asked 
to give details of the circumstances under which each diagnosis of Paget's disease had been made.

Occupations were coded according to the Office of Population Censuses and Surveys 1970 classification $^{14}$ and illnesses according to the International Classification of Diseases. ${ }^{15}$ For the purpose of analysis each known place of birth or residence was specified by one of the 120 outer postcode areas in the United Kingdom (the single or double letter code at the beginning of the complete postcode) or by country if abroad.

\section{Results}

COMPOSITION OF THE SAMPLE AND PREVALENCE AMONG RELATIVES

A total of 407 questionnaires were returned completed, a response rate of $68 \%$, the mean age of index cases being 73 years. Table 1 gives the numbers of different types of relative who had survived to at least 55 and the numbers affected by Paget's disease. The prevalence of the disease among parents and siblings of index cases $(57 / 1450=3.93 \%)$ was about 10 times greater than among parents and siblings of spouses $(3 / 823=0 \cdot 36 \%)$, and the same degree of female predominance was found among parents and siblings of index cases $\left(q / \sigma^{\prime}=37 / 20=1 \cdot 85\right)$ as among the index cases themselves $(~ \& / 0=255 / 152=1 \cdot 68)$. There was no significant difference of prevalence between the parents of index cases and the siblings of index cases at age 55 and above. After combining parents and siblings there was no significant difference between male and female index cases in the proportions of these relatives affected. Nevertheless, male index cases differed from female index cases in that they had significantly $(p<0.01)$ fewer affected male relatives (fathers and brothers) than affected female relatives (mothers and sisters).
Of the 407 index cases, $56(13.8 \%)$ had a family history of Paget's disease. Of these 56 familial cases, 31 came from families where successive generations were affected ("dominant") and 25 from families where only siblings were affected ("recessive"). Overall, there were 42 concordant parent-offspring pairs, 17 involving fathers (three of which were father-son pairs) and 25 involving mothers. Among the 33 sibships that contained more than one individual reported to have Paget's disease there were 39 sibling pairs concordant and 194 sibling pairs discordant for the disease.

\section{ONSET OF PAGET'S DISEASE}

The mean age of onset (awareness of having the disease) was significantly earlier among familial than among isolated cases (table 2), but there was no difference between dominant and recessive cases. The within family variance for age of onset was significantly lower than the between family variance, indicating that relatives tended to be more alike with respect to age of onset than unrelated individuals, and the within sibship variance for year of onset was significantly greater than that for age of onset (table 3). .

Only two unusual circumstances occurring within the year preceding onset were each reported by more than $1 \%$ of the total of 480 cases (index cases plus affected relatives), a fall in 23 patients $(4 \cdot 8 \%)$ and a road accident in six patients $(\mathbf{1} \cdot \mathbf{3 \%})$.

\section{OTHER CHRONIC ILLNESSES}

Index cases were asked if they or their relatives suffered from any chronic illness or disability other than Paget's disease, and if so to name the one that was the most troublesome. The distribution of the most troublesome other chronic illnesses showed a significant difference $(p<0.001)$ between index cases on the one hand and normal living siblings and

Table 1 Numbers of different types of relative who survived to at least age 55 and the numbers and percentages affected by Paget's disease. Numbers of index cases in parentheses

\begin{tabular}{|c|c|c|c|c|c|c|c|c|c|}
\hline \multirow[b]{3}{*}{ Type of relative } & \multicolumn{3}{|c|}{ Male index (152) } & \multicolumn{3}{|c|}{ Female index (255) } & \multicolumn{3}{|c|}{ Both sexes (407) } \\
\hline & \multirow[b]{2}{*}{ Total } & \multicolumn{2}{|c|}{ Affected } & \multirow[b]{2}{*}{ Total } & \multicolumn{2}{|c|}{ Affected } & \multirow[b]{2}{*}{ Total } & \multicolumn{2}{|c|}{ Affected } \\
\hline & & No & $\%$ & & No & $\%$ & & No & $\%$ \\
\hline Fathers & 113 & 1 & 0.88 & 172 & 11 & $6 \cdot 40$ & 285 & 12 & $4 \cdot 21$ \\
\hline Mothers & 119 & 8 & 6.72 & 183 & 7 & $3 \cdot 83$ & 302 & 15 & 4.97 \\
\hline Brothers & 148 & 1 & 0.68 & 257 & 7 & $2 \cdot 72$ & 405 & 8 & 1.98 \\
\hline Sisters & 166 & 6 & $3 \cdot 61$ & 292 & 16 & $5 \cdot 48$ & 458 & 22 & $4 \cdot 80$ \\
\hline Sons & 4 & $\mathbf{0}$ & 0.0 & 20 & 0 & 0.0 & 24 & 0 & 0.0 \\
\hline Daughters & 12 & 0 & 0.0 & 23 & 0 & 0.0 & 35 & 0 & 0.0 \\
\hline Male spouses & - & - & - & 146 & 0 & 0.0 & 146 & 0 & 0.0 \\
\hline Female spouses & 110 & 0 & 0.0 & - & - & - & 110 & 0 & 0.0 \\
\hline Spouses' fathers & 81 & 0 & 0.0 & 99 & 0 & 0.0 & 180 & 0 & 0.0 \\
\hline Spouses' mothers & 94 & 2 & $2 \cdot 13$ & 103 & 0 & 0.0 & 197 & 2 & 1.02 \\
\hline Spouses' brothers & 95 & 0 & 0.0 & 124 & 1 & 0.81 & 219 & 1 & 0.46 \\
\hline Spouses' sisters & 107 & 0 & 0.0 & 120 & 0 & 0.0 & 227 & 0 & 0.0 \\
\hline
\end{tabular}


spouses' siblings on the other, deafness and arthropathy being reported more often among index cases.

Table 2 Mean age of onset for isolated and familial cases

$\left.\begin{array}{lclllll}\hline & \text { No } & \begin{array}{c}\text { Mean age of } \\ \text { onset (years) }\end{array} & S E & \text { Diff } & t & p \\ \hline \text { Isolated } & 327 & 56.98 & 0.72 \\ \text { Familial } & 95 & 53.49 & 1.38\end{array}\right\}$

OCCUPATION AND SOCIAL CLASS

Male index cases were compared with normal male siblings of cases and female index cases with normal female siblings of cases. For both sexes a greater proportion of index cases than of normal siblings was engaged in non-manual work. The proportions in men were $54 \%$ as opposed to $47 \%$ and in women $71 \%$ as opposed to $59 \%$. The difference was significant for women $(p<0 \cdot 01)$. In particular, there was an excess of index cases in occupation unit groups 24 (administrators and managers) and 25 (professionals, technical workers, and artists). Some $26 \%$ of male index cases fell into these groups compared with $16 \%$ of normal male siblings, and $23 \%$ of female index cases fell into these groups compared with $12 \%$ of normal female siblings. The difference was significant both for men $(p<0.01)$ and for women $(p<0 \cdot 001)$. Normal siblings of spouses were also less likely to be engaged in non-manual work and to be in occupation unit groups 24 and 25 than index cases but none of the differences was statistically significant.

The distribution of social class among index cases showed a significant $(\mathrm{p}<0.005)$ over-representation of the higher classes compared with the general population. ${ }^{16}$

\section{PLACES OF BIRTH AND RESIDENCE}

Table 4 shows the distribution of concordant and discordant sibling pairs from the 33 sibships that each contained more than one case of Paget's disease. The two members of each pair were classified as having been born or having had their main place of residence over three age ranges in either the same or different postcode areas. There was no significant tendency for concordant pairs to have been born or to have lived in the same postcode area and for discordant pairs to have been born or to have lived in different postcode areas. A similar analysis was carried out using all sibships of index cases, comparing those having only a single case of Paget's disease with the 33 multiple case sibships. Sibships were classified as all members born or having lived in either a single postcode area or multiple postcode areas. There was no significant association between single postcode areas and multiple case sibships, either for place of birth or for main place of residence in any of the three age ranges.

\section{YEAR OF BIRTH}

Among the index cases there appeared to be a fluctuating distribution of years of birth with a periodicity of around three years (fig 1a), reminiscent

Table 3 Analysis of variance for age of onset and comparison of within sibship variances for year ofonset and age of onset

$\left.\begin{array}{lrrrr}\hline & s s & d f & \text { Mean square } & \text { F } \\ \hline \text { Age of onset between families } & 11486 & 35 & 328 \cdot 17 \\ \text { Age of onset within families } & 3720 & 40 & 93 \cdot 12\} & 3.52 \\ \text { Year of onset within sibships } & 4759 & 29 & 164 \cdot 29 \\ \text { Age of onset within sibships } & 2162 & 29 & 74.63\end{array}\right\}$

$s s=$ Sum of squares.

$F=$ Variance ratio.

Table 4 Distribution of sibling pairs concordant and discordant for Paget's disease from 33 sibships by postcode area of birth and main postcode area of residence over three age ranges

\begin{tabular}{|c|c|c|c|c|c|c|c|c|}
\hline \multirow[b]{2}{*}{ Postcode area } & \multicolumn{2}{|l|}{ Birth } & \multicolumn{2}{|c|}{$0-20$ years } & \multicolumn{2}{|c|}{$21-40$ years } & \multicolumn{2}{|c|}{$>40$ years } \\
\hline & Same & Diff & Same & Diff & Same & Diff & Same & Diff \\
\hline $\begin{array}{l}\text { Concordant pairs } \\
\text { Discordant pairs }\end{array}$ & $\begin{array}{r}30 \\
159\end{array}$ & $\begin{array}{r}9 \\
33\end{array}$ & $\begin{array}{r}35 \\
157\end{array}$ & $\begin{array}{r}4 \\
31\end{array}$ & $\begin{array}{l}18 \\
94\end{array}$ & $\begin{array}{l}21 \\
72\end{array}$ & $\begin{array}{l}18 \\
70\end{array}$ & $\begin{array}{l}21 \\
84\end{array}$ \\
\hline $\begin{array}{l}x^{2} \\
\mathrm{p}\end{array}$ & \multicolumn{2}{|c|}{0.41} & \multicolumn{2}{|c|}{0.54} & \multicolumn{2}{|c|}{$1 \cdot 01$} & \multicolumn{2}{|c|}{0.01} \\
\hline
\end{tabular}

NS = Not significant. 
of the cyclic changes in prevalence known to occur for various infectious diseases. Such fluctuations could be the result of cyclic changes of birth rate or differences in longevity associated with different years of birth, independent of Paget's disease. Accordingly, the number of index cases known to have been born in England and Wales in each year was expressed as a proportion of all persons with the same year of birth in the total population of England and Wales at $\mathbf{3 1}$ December 1980. The total population figures used were unpublished estimates provided by the population estimates unit of the Office of Population Censuses and Surveys. Figure $1 \mathrm{~b}$ shows that after this adjustment the fluctuations in relative frequency of different birth years remain. Using standard statistical tests, however, no significant cyclic variation for any given periodicity was found in the relative frequency of cases of Paget's disease for different years of birth.

\section{Discussion}

\section{GENETICS}

Previous investigations into the genetics of Paget's disease have been of two types: pedigree studies, those concerned with the pattern of distribution of
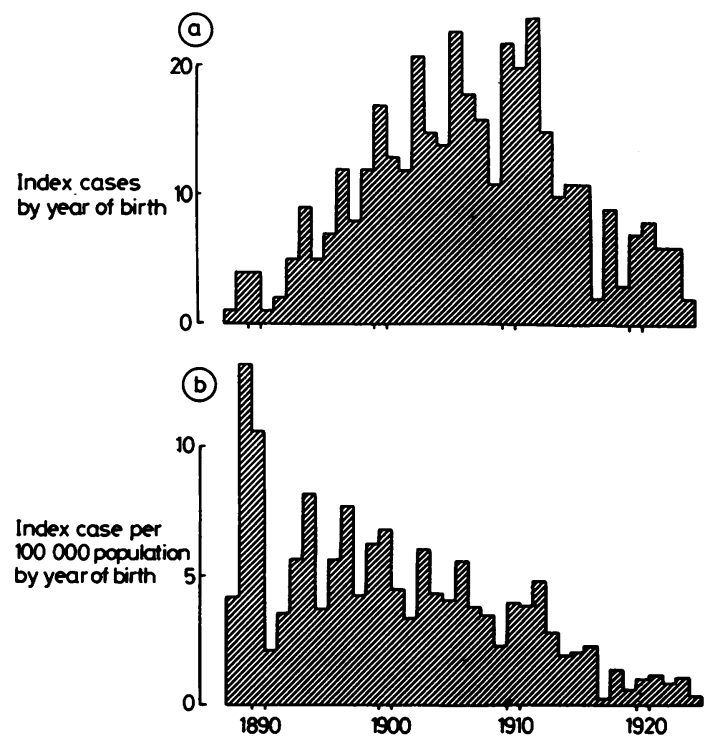

(a) Distribution of the 386 index cases born from 1888 to 1924 by year of birth. (b) Number of index cases born in England and Wales in each year from 1888 to 1924 (total 347) as a proportion of all persons with the same year of birth in the total population of England and Wales at 31 December 1980. the disease in selected families; and studies of prevalence among relatives of unselected samples of index cases. The pedigree data ${ }^{17-20}$ appear to be consistent with dominant inheritance and reduced penetrance. The results of the present study are compatible with this, there being no detectable difference between dominant and recessive cases. Nevertheless, there are two main difficulties of interpretation. Firstly, there is the variable but generally rather late onset of the disease and, secondly, the lack of uniformity of diagnostic criteria, in particular the absence of symptoms in a large proportion of those who, on radiological evidence, would be regarded as having the disease. Conventional segregation analysis is therefore not appropriate, and it seems necessary, at least initially, to resort to simple quantitative expressions of the familial nature of the disease. Table 5 illustrates the wide range in the proportion of cases reported to have had a positive family history. This variation may simply reflect differences in the level of diagnosis.

In the present study the 10 -fold higher prevalence of Paget's disease among parents and siblings of index cases $(3.93 \%)$ compared with parents and siblings of spouses $(0.36 \%)$ both illustrates the familial nature of the disease and gives some indication of the overall level of detection. The prevalence of radiological evidence of the disease at age 55 and above is around $5 \%$ in the United Kingdom $^{1}$ so, if parents and siblings of spouses are regarded as representative of the general population, only $7 \%$ of those with radiological signs have been detected by the questionnaire. This is in good agreement with the usually quoted figure of $5 \%$ for the proportion of affected individuals who have symptoms. ${ }^{27}$

The female predominance observed, which occurred both among index cases and among parents and siblings of index cases, appears to conflict with the generally reported male predominance. This finding could perhaps be explained by the more frequent general practitioner consultations of women, ${ }^{28}$ leading to a higher probability of detection of mild or asymptomatic cases and therefore a higher degree of self awareness for the disease among women.

Table 5 Numbers and proportions of cases of Paget's disease reported to have had a positive family history

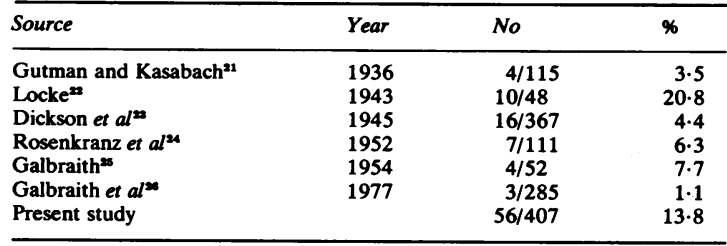


The difference between isolated and familial cases for mean age of onset (table 2) is consistent with different levels of genetic contribution to the two types of case but could also be explained by the likelihood of earlier diagnosis in families already known to contain an affected individual. Likewise, the similarity of age of onset within families (table 3 ) could be caused either by common genes or by common environmental influences. The greater within sibship variance of year of onset compared with age of onset (table 3), however, suggests that onset is influenced more by the length of time that has elapsed since birth than by any environmental factor of short duration affecting members of the same sibship together. This is in keeping with a genetic influence on age of onset, but does not exclude an origin for the disease through the effect of a common and widespread environmental agent acting at or around the time of birth, or of long term environmental effects.

It is possible to estimate the heritability of "self knowledge of Paget's disease" using the method of Falconer, ${ }^{29}$ assuming that "self knowledge" constitutes the more severe extreme of the distribution of those with radiological signs. Barker et al have given the overall British prevalence of radiological signs in those aged 55 and above as $6.2 \%$ for men and $3.9 \%$ for women. ${ }^{1}$ Assuming that only $5 \%$ of those with radiological signs are aware that they have the disease, the population prevalence of self knowledge is then $0.31 \%$ for men and $0.20 \%$ for women. Using the figures for prevalence among parents and siblings who survived to at least 55 (table 1), the heritabilities calculated for self knowledge of Paget's disease are $21 \pm 17 \%$ for men and $77 \pm 6 \%$ for women. The relatively low estimate and high standard error for men are due to the fact that so few male index cases had affected male relatives.

\section{OTHER FACTORS}

The reporting of a fall or a road accident within the year before onset is more plausibly explained in terms of detection of existing disease after radiography for injury, particularly because of the predisposition to fracture, rather than in terms of a traumatic origin for Paget's disease. Deafness and arthropathy are known complications of Paget's disease, so the reporting of these disabilities as the most troublesome other chronic illness more often among index cases was to be expected and provides no new information on the aetiology of Paget's disease.

The excess of index cases in occupation unit groups 24 and 25 , compared with normal siblings, is difficult to interpret but appears unlikely to reflect an occupational component in the pathogenesis of the disease. If anything, it might be expected that those doing manual rather than non-manual work would be more likely to know of any Paget's disease present since physical stress is thought to encourage development of the disease. ${ }^{30}$ On the other hand, it is possible that some of the deficiency of cases involved in manual work could have been caused by the more severely affected changing to more sedentary jobs after the onset of disability. The over-representation of the higher social classes may be plausibly explained by better access to medical services ${ }^{31}$ and therefore greater likelihood of diagnosis, and by greater readiness of those in the higher social classes to become members of the National Association for the Relief of Paget's Disease and to complete the questionnaire. ${ }^{32}$ The present data thus provide no convincing evidence that either occupation or social class contributes to the aetiology of Paget's disease.

Geographical location has been shown to have a pronounced influence on the prevalence of Paget's disease at the population level. ${ }^{156}$ It was not possible, however, to show an association between geographical location and Paget's disease either within sibships (table 4) or between sibships in the present sample. Any contribution to resemblance between relatives made by a common geographical location is therefore likely to be small, although, because of the large size of certain postcode areas, very localised clustering of concordant siblings could have occurred undetected.

Failure to show statistically significant cyclic variation in the distribution of years of birth for index cases could perhaps have been due to the small number of cases born in any particular year and to the fact that the three year periodicity was not present over all years studied. If future investigations are able to confirm the existence of cyclic variation in relative frequency of different years of birth for patients with Paget's disease this would be suggestive of an infectious aetiology, with infection occurring at or around the time of birth. It is relevant to note that most cases of serious infection by respiratory syncytial virus are found in infants under 12 months old, with the peak incidence at 1-2 months. This is in pronounced contrast to measles, against which a degree of protection during the first year of life is afforded by maternal antibody and where the age at infection is much more variable. ${ }^{33} \mathrm{~A}$ more pronounced year of birth effect would therefore be expected from respiratory syncytial virus than from measles.

\section{Conclusions}

The familial nature of Paget's disease of bone has 
A family study of Paget's disease of bone

been confirmed. The aetiology of the disease is likely to be independent of other illnesses, occupation, and social class. Similarity between relatives with respect to presence or absence of the disease is more readily explained by common genes than by common environment. Variation in age of onset of the disease may also have a genetic basis. The findings of the present study are consistent with the hypothesis that Paget's disease results from infection by a common and widespread virus, possibly at or around the time of birth, superimposed on genetic variation for susceptibility and perhaps severity of the disease. Further investigations of the possible year of birth effect might provide epidemiological support for the viral hypothesis.

We thank the National Association for the Relief of Paget's Disease for financial support and access to their members, the patients themselves for their cooperation, Mrs Loraine Williamson for clerical help, and Dr A M Davie and Mrs G M Raab for statistical advice in relation to cyclic variation. Dr J Davies of the Royal National Hospital for Rheumatic Diseases, Bath, and Dr Roger Smith of the Nuffield Orthopaedic Centre, Oxford, kindly contributed a small number of cases.

\section{References}

${ }^{1}$ Barker DJP, Chamberlain AT, Guyer PB, Gardner MJ. Paget's disease of bone: the Lancashire focus. $\mathrm{Br} \mathrm{Med} J$ 1980; i: 1105-7.

${ }^{2}$ Williams NJ, ed. Diphosphonates and Paget's disease. $\mathrm{Br}$ $J$ Clin Pract 1981; symp suppl 13.

${ }^{3}$ McKusick VA. Mendelian inheritance in man. 5th ed. Baltimore: The Johns Hopkins University Press, 1978: 294-5.

${ }^{4}$ Fotino M, Haymovits A, Falk CT. Evidence for linkage between HLA and Paget's disease. Transplant Proc 1977; 9: 1867-8.

${ }^{5}$ Gardner MJ, Guyer PB, Barker DJP. Radiological prevalence of Paget's disease of bone in British migrants to Australia. Br Med J 1978; i: 1655-7.

${ }^{6}$ Guyer PB, Chamberlain AT. Paget's disease of bone in two American cities. Br Med J 1980; i: 985.

${ }^{7}$ Singer FR. Paget's disease of bone: a slow virus infection? Calcif Tiss Int 1980; 31: 185-7.

${ }^{8}$ Rebel A, Basle K, Malkani K. Towards a viral aetiology for Paget's bone disease. Br J Clin Pract 1981; symp suppl 13: 9-14.
${ }^{9}$ Mills BG, Singer FR, Weiner LP, Holst PA. Immunohistological demonstration of respiratory syncytial virus antigens in Paget's disease of bone. Proc Natl Acad Sci USA 1981; 78: 1209-13.

${ }^{10}$ Mills BG, Stabile E, Holst P, Graham C. Antigens of two different viruses in Paget's disease of bone.J Dent Res 1982; 61: 347.

${ }^{11}$ Morgan-Capner P, Robinson P, Clewley G, Darby A, Pettingale K. Measles antibody in Paget's disease. Lancet 1981; i: 733.

${ }^{12}$ Winfield J, Sutherland S. Measles antibody in Paget's disease. Lancet 1981; i: 891.

${ }^{13}$ Singer FR, Mills BG, Weiner LP. Elevated serum paramyxovirus antibodies in patients with Paget's disease of bone. Clin Res 1978; 26: 533A.

${ }^{14}$ Office of Population Censuses and Surveys. Classification of occupations. London: HMSO, 1970.

${ }^{15}$ World Health Organisation. International classification of diseases. Geneva: WHO, 1978.

${ }^{16}$ Reid I. Social class differences in Britain. London: Open Books, 1977.

${ }^{17}$ Montague MFA. Paget's disease (osteitis deformans) and heredity. Am J Hum Genet 1949; 1: 94-5.

${ }^{18}$ McKusick VA. Paget's disease of the bone. In: Heritable disorders of connective tissue. 3rd ed. St Louis: Mosby, 1972: 304-9.

19 Jones JV, Reed MF. Paget's disease: a family with six cases. Br Med J 1967; iv: 90-1.

${ }^{20}$ Evens RG, Bartter FC. The hereditary aspects of Paget's disease (osteitis deformans). JAMA 1968; 205: 900-2.

${ }^{21}$ Gutman AB, Kasabach HH. Paget's disease (osteitis deformans): analysis of 116 cases. Am J Med Sci 1936; 191: 361-80.

${ }^{22}$ Locke EA. Quoted by Galbraith. ${ }^{26}$

${ }^{23}$ Dickson DD, Camp JD, Ghormley RK. Osteitis deformans: Paget's disease of the bone. Radiology 1945; 44: 449-70.

${ }^{24}$ Rosenkrantz JA, Wolf J, Kaicher JJ. Paget's disease (osteitis deformans); review of 111 cases. Arch Int Med 1952; 90: 610-33.

${ }^{25}$ Galbraith, H-JB. Familial Paget's disease of bone. Br Med J 1954; ii: 29.

${ }^{26}$ Galbraith H-JB, Evans EC, Lacey J. Paget's disease of bone-a clinical and genetic study. Postgrad Med J 1977; 53: 33-9.

${ }^{27}$ Smith R. Modern treatment of Paget's disease of bone. Prescribers' Journal 1982; 22: 23-31.

${ }^{28}$ Office of Population Censuses and Surveys. The general household survey. Introductory report. London: HMSO, 1973.

${ }^{29}$ Falconer DS. The inheritance of liability to certain diseases, estimated from the incidence among relatives. Ann Hum Genet 1965; 29: 51-76.

${ }^{30}$ Guyer PB. Bone stress as a factor in the pathogenesis of osteitis deformans. Br J Clin Pract 1981; symp suppl 13: 15-8.

${ }^{31}$ Townsend $\mathrm{P}$, Davidson $\mathrm{N}$, eds. Inequalities in health. The Black report. Harmondsworth: Penguin Books, 1982.

${ }^{32}$ Sheikh K, Mattingly S. Investigating non-response bias in mail surveys. J Epidemiol Community Health 1981; 35: 293-6.

${ }^{33}$ Fenner F, White DO. Medical virology. 2nd ed. New York: Academic Press, 1976: 386-405. 